\title{
The Wear Characteristics of Wet Clutch in the DCT Vehicle During the Launching Process
}

\author{
Qianqian Zhang, Man Chen, Biao Ma, Jianpeng Wu, Liang Yu \\ School of Mechanical Engineering \\ Beijing Institute of Technology, Beijing, China \\ 13041210646@163.com; turb911@bit.edu.cn
}

\begin{abstract}
In order to investigate the wear characteristics of wet clutch during the vehicle launching process, the experimental investigations and the dynamic analysis are conducted in the study. Firstly, the wet pin-on-disc experiment is designed to explore the wear behaviours of the wet friction pair. Based on the experimental results under various conditions, the wear amount is measured by the multielement oil analysis spectrometer and the corresponding wear coefficient is deduced according to the Archard laws. After that, the dynamic model of the Double Clutch Transmission (DCT) vehicle is established to study the wear condition of the wet clutch during the vehicle launching process. The experimental and simulation results indicate that, the increase of the slipping speed, the contact pressure and the temperature leads to the increase of the wear amount, while, for the wear coefficient, the slipping speed has little influence. During the vehicle launching process, the driver's gentle operation with light vehicle load will reduce the wear a mount of the wet clutch and prolong its service life.
\end{abstract}

Keywords: Friction and wear, Pin-on-disc experiment, Wet clutch, Dual clutch transmission, Launching process.

\section{Introduction}

DCT is a new type of automatic transmission developed on the basis of manual transmission (MT) and automatic manual transmission (AMT). It carries on the features of simple structure, high efficiency and low manufacturing cost as MT; in addition, it has the advantages of achieving swiftly and seamlessly gearshifts without power interruption, compared with automatic manual transmission (AMT) [1]. As illustrated in Fig. 1, the wet clutch, consisting of steel discs and friction discs, is the core component in DCT. When the friction disc and steel disc slip during the clutch engagement process, the wear of the friction disc will occur. That will definitely influence the dynamic performance and the service life of the clutch. Therefore, the exploration of the wear characteristics of the wet clutch is one of the keys to improve the DCT performance.

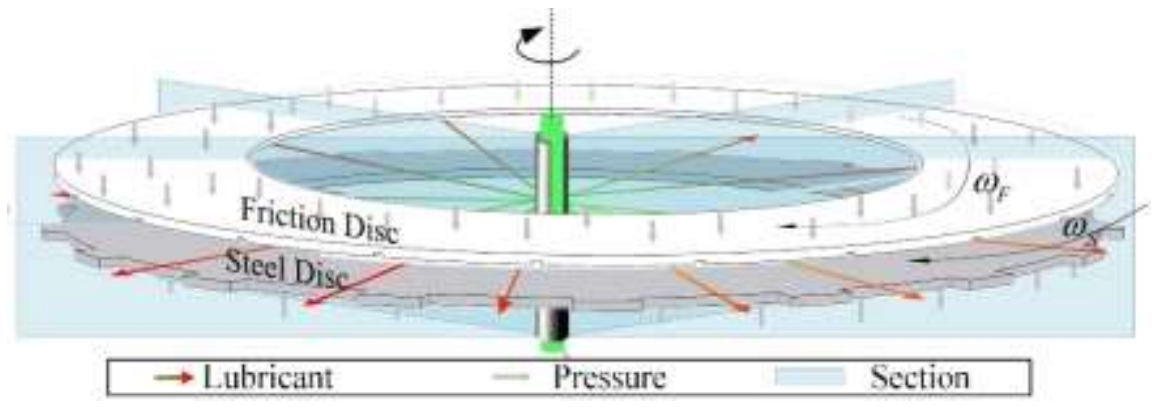

Fig. 1: Diagram of friction pair for wet clutch.

In the previous research, the dynamics characteristics of DCT is analysed emphatically by building the dynamic model of the integrated vehicle [2,3]. In order to arrange the transmitted torque by two clutches effectively, coordinated control between the engine and DCT is studied and achieved [4, 5]. Besides, to engage the on-coming clutch smoothly during the shifting or launching process, many control theories, for instance the linear quadratic optimal control and the fuzzy PID control, are introduced [6-8]. And the obtained simulation and experimental results indicate the effectiveness of the proposed control methods, the dynamic performance of the DCT vehicle has been improved significantly. However, when it comes to the wear problem of the wet clutch in the DCT, although the adhesive wear theory, the energy wear theory and the 
delamination wear theory are proposed [9-11], further investigations of the wear characteristics are still required improve the DCT performance.

The paper is organised as follows. In the second section, a wet pin-on-disc experiment is designed firstly to investigate the wear condition of the wet friction pair, including the wear amount and the wear coefficient under different conditions. As for the third section, the powertrain model of DCT vehicle is established in order to describe the dynamic characteristics of the vehicle. After that, in the section 4, different factors are considered to analysis the influence on the wear amount of the wet clutch in DCT taking the launching process as an example. Finally, the conclusions are presented.

\section{Experiment of the wet friction pair}

The high temperature tribometer, shown in Fig. 2, is adopted to study and simulate the friction and wear behaviours during the clutch engagement process. This equipment consists of the wet rotation module, the sensor module, the temperature control module, the loading module and the data acquisition module, etc.

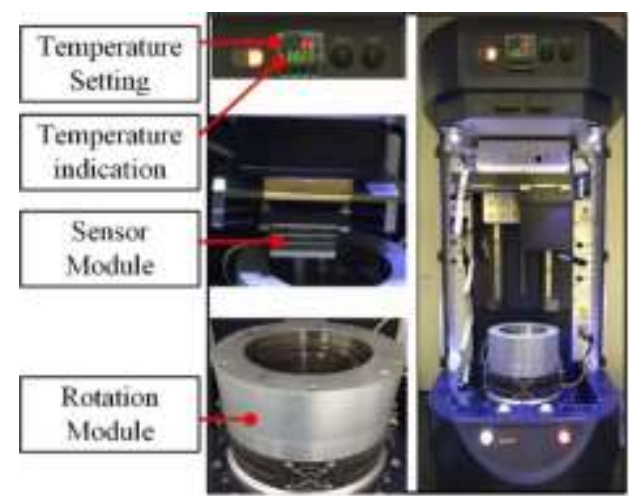

Fig. 2: The high temperature tribometer.

The temperature range is $0 \sim 150^{\circ} \mathrm{C}$ and the control precision is $\pm 3{ }^{\circ} \mathrm{C}$. The pin-on-disc experiment sample, as shown in Fig.3, is made of the same material as the wet clutch, including the 65Mn steel (the dowel) and the copper-base powder metallurgy material (the friction disc). The diameter of the dowel is $6 \mathrm{~mm}$, and the effective friction radius of the disc is $25 \mathrm{~mm}$. As presented in Fig. 4, the dowel is fixed to the sensor module with a downward load and the disc is fixed on the platform and rotates with the platform together.

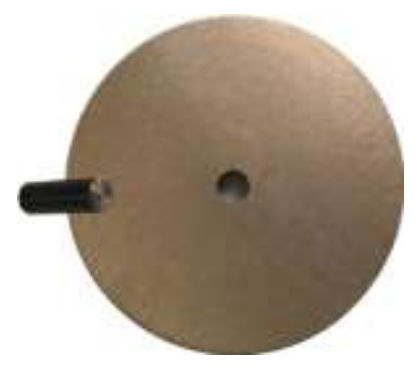

Fig. 3: Sample of the pin-on-disc experiment.

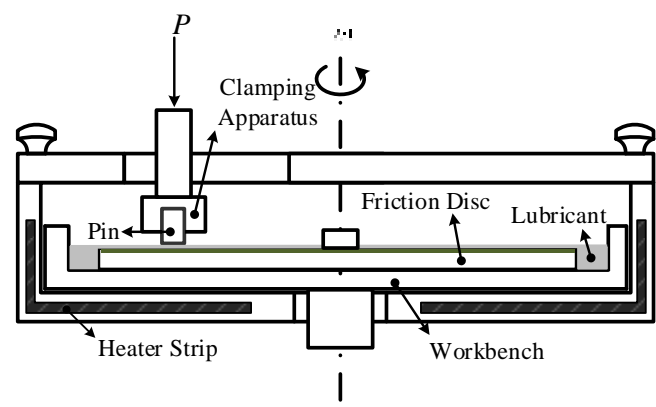

Fig. 4: Rotation module structure diagram.

After the fully grinding-in process, the friction experiment is proposed as follows: (1) Clean the lubricating oil pool and fill 30mL bran-new lubricating oil. (2) Heat the specimen to the target temperature. (3) Adjust motor to the target speed and engage the friction pair. (4) Record the related data during the $30 \mathrm{~min}$ slipping time. (5) Finish the slipping 
process and separate the friction pair. (6) Collect all the lubricating oil and clean the pool. Repeat the above steps according to the conditions listed in the Table 1.

Table 1: Different experiment conditions.

\begin{tabular}{|c|c|}
\hline Parameters & Value \\
\hline Temperature $\left({ }^{\circ} \mathrm{C}\right)$ & $30,60,90,120,150$ \\
\hline Load $(\mathrm{N})$ & $20,40,60,80,100,120,140$ \\
\hline Average interface contact pressure $(\mathrm{MPa})$ & $0.7,1.4,2.1,2.8,3.5,4.2,4.9$ \\
\hline Rotating speed $(\mathrm{r} / \mathrm{min})$ & $1,10,100,400,600,800,1500$ \\
\hline Velocity $(\mathrm{mm} / \mathrm{s})$ & $2.6,26,261,1047,1571,2095,3927$ \\
\hline
\end{tabular}

As the concentration of the copper element is different in the lubricating oil before and after the experiment, the wear amount of friction disc can be calculated according to the analysis by the multielement oil analysis spectrometer, shown in Fig.5. The working principle of the oil spectrum analysis is shown in Fig.6.

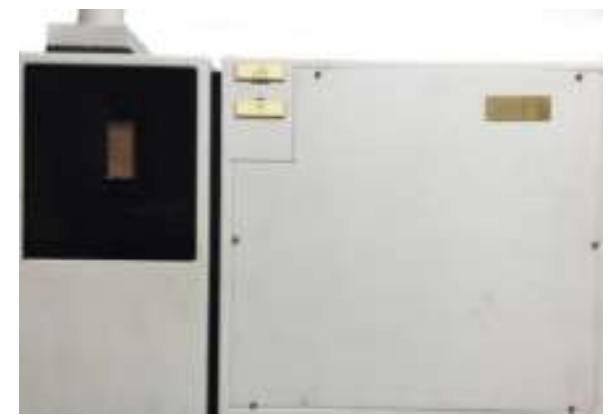

Fig. 5: The multielement oil analysis spectrometer.

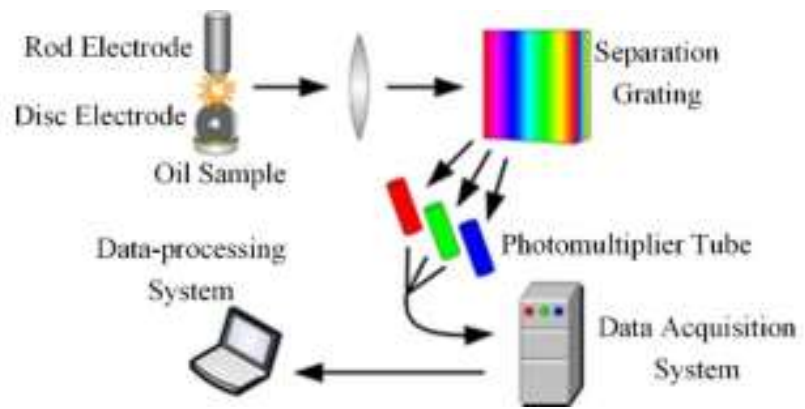

Fig. 6: The working principle of oil spectrum analysis.

After obtaining the wear amount of the friction disc, the Archard laws [9] is introduced to deduce the wear coefficient of the wet friction pair according to the corresponding the experimental data.

$$
K_{\delta}=\frac{\varphi_{\text {test }}}{A_{\text {test }} p_{c} S}
$$

Part of the experimental results and the calculated wear coefficient are shown in Fig.7 and Fig.8 respectively. It can be seen that the wear amount shows a growing trend with the increase of temperature, pressure and relative velocity, but the wear coefficient shows a different changing trend. In Fig.8(a), even the slipping speed increases from 1047mm/s to $2095 \mathrm{~mm} / \mathrm{s}$, the value of the wear coefficient slightly fluctuated; however, with the increase of the pressure and the temperature, the value of the wear coefficient shows an obvious growing up trend. 


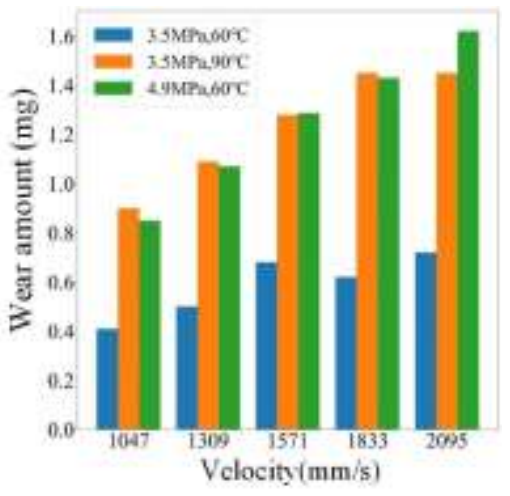

(a)

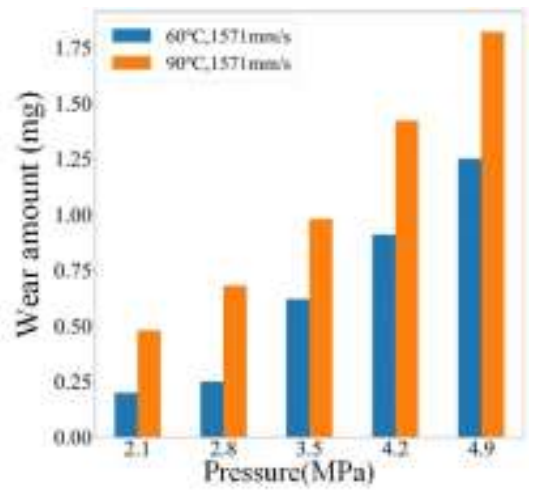

(b)

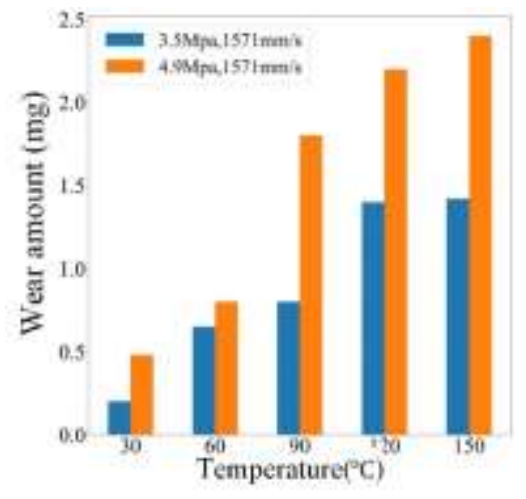

(c)

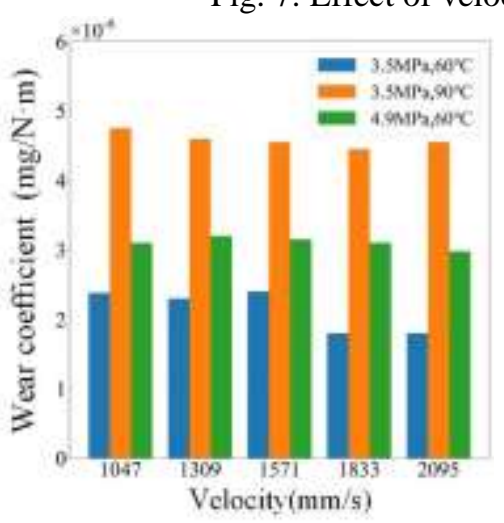

(a)

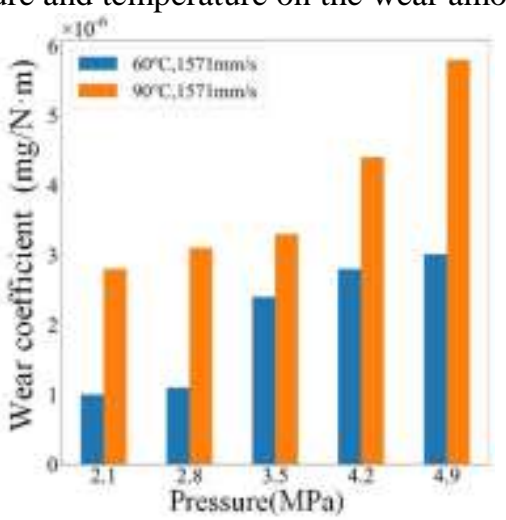

(b)

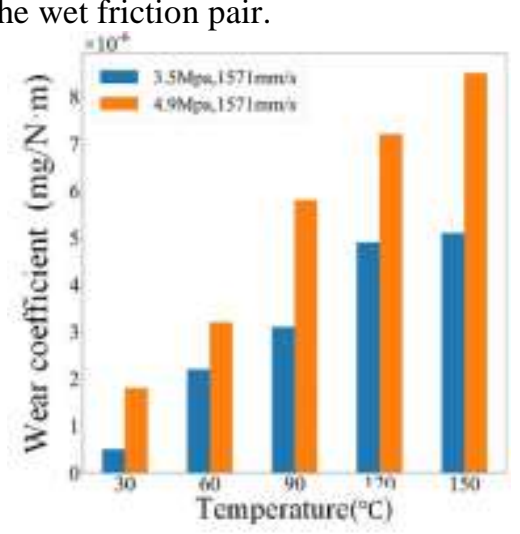

(c)

Fig. 8: Effect of velocity, pressure and temperature on the wear coefficient of the wet friction pair.

Based on the above experimental results, it can be concluded that the slipping speed has little influence on the wear coefficient. Thus, the changing trend of the wear coefficient is obtained by thin plate spline interpolation method, regarding the temperature and the contact pressure. As shown in Fig.9, the wear coefficient varies basically within the limitation of $0 \sim 8 \times 10^{-6} \mathrm{mg} / \mathrm{N} \cdot \mathrm{m}$. 


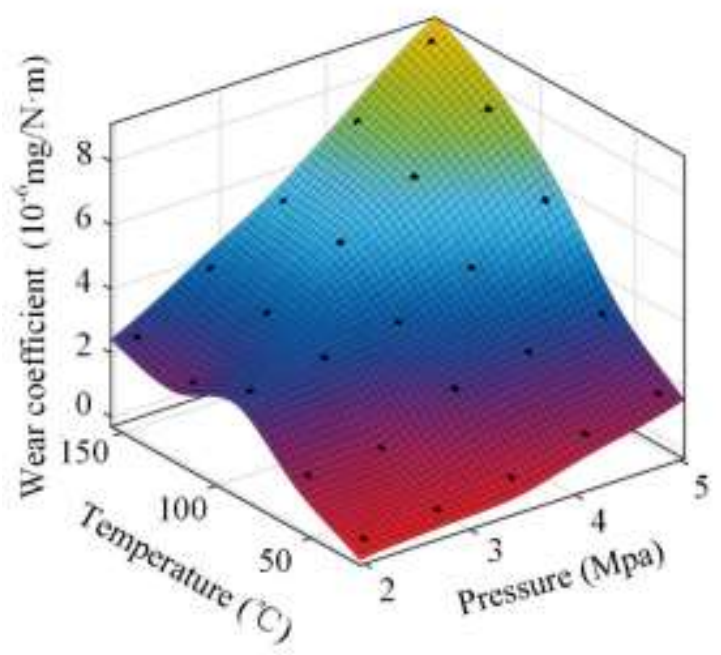

Fig. 9: Variation trend of wear coefficient.

\section{Integrated model of the DCT vehicle}

In order to investigate the wear condition of the wet clutch during the DCT vehicle launching process, an integrated powertrain model is developed. According to the traditional methods, the powertrain system of the vehicle is modeled as a lumped inertial element connected with the corresponding stiffness and damping components, which is shown in Fig. 10.

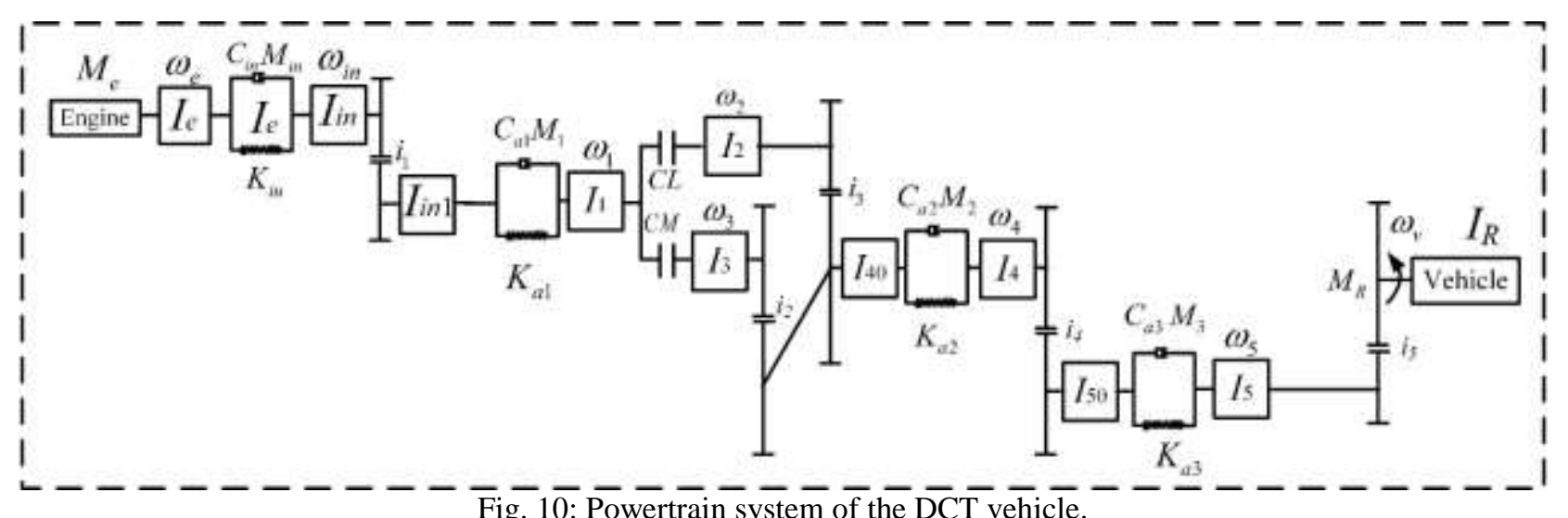

When DCT starts with only slipping CL, the dynamic equations can be deduced following the Newton's second theorem.

$$
\begin{gathered}
I_{e} \frac{d \omega_{e}}{d t}=M_{e}-M_{\text {in }} \\
\left(I_{\text {in }}+\frac{I_{\text {in } 1}}{i_{1}^{2}}\right) \frac{d \omega_{\text {in }}}{d t}=M_{\text {in }}-\frac{M_{1}}{i_{1}} \\
I_{1} \frac{d \omega_{1}}{d t}=M_{1}-M_{C L}
\end{gathered}
$$




$$
\begin{gathered}
\left(I_{2}+\frac{I_{40}}{i_{3}{ }^{2}}\right) \frac{d \omega_{2}}{d t}=M_{C L}-\frac{M_{2}}{i_{3}} \\
\left(I_{4}+\frac{I_{50}}{i_{4}{ }^{2}}\right) \frac{d \omega_{4}}{d t}=M_{2}-\frac{M_{3}}{i_{4}} \\
\left(I_{5}+\frac{I_{50}}{i_{4}{ }^{2}}\right) \frac{d \omega_{3}}{d t}=M_{3}-\frac{M_{r}}{i_{5}} \\
M_{\text {in }}=K_{\text {in }}\left(\theta_{e}-\theta_{\text {in }}\right)+C_{\text {in }}\left(\omega_{e}-\omega_{\text {in }}\right) \\
M_{1}=K_{a 1}\left(\frac{\theta_{i n}}{i_{1}}-\theta_{1}\right)+C_{i n}\left(\frac{\omega_{i n}}{i_{1}}-\omega_{1}\right) \\
M_{2}=K_{a 2}\left(\frac{\theta_{2}}{i_{3}}-\theta_{4}\right)+C_{a 2}\left(\frac{\omega_{2}}{i_{3}}-\omega_{4}\right) \\
M_{3}=K_{a 3}\left(\frac{\theta_{4}}{i_{4}}-\theta_{5}\right)+C_{a 3}\left(\frac{\omega_{4}}{i_{4}}-\omega_{5}\right) \\
M_{R}=\left(\frac{1}{2} \rho_{a i r} C_{D} A v_{e}{ }^{2}+m g f \cos \beta+m g \sin \beta+\delta m \frac{d v_{e}}{d t}\right) r_{w} \\
M_{C L}=\mu \mathrm{N} P_{C} A_{f} \frac{2}{3}\left(\frac{R_{o}{ }^{3}-R_{i}{ }^{3}}{R_{o}{ }^{2}-R_{i}{ }^{2}}\right)
\end{gathered}
$$

For the engine output torque, it is modeled as a mean value torque generator, described as a function of throttle opening and engine rotation speed [12], and other value of the above mentioned parameters are listed in the Appendix.

\section{Simulation results analysis}

With the integrated powertrain model to calculate the contact pressure, the sliding speed and the temperature variation of the wet clutch during the DCT vehicle launching process, the wear amount of the clutch can be obtained. The simulation results under variation conditions are presented in the Fig.11 to study the influence of different factors, including the road slope, the road types, the environment temperature and the driver's intention.

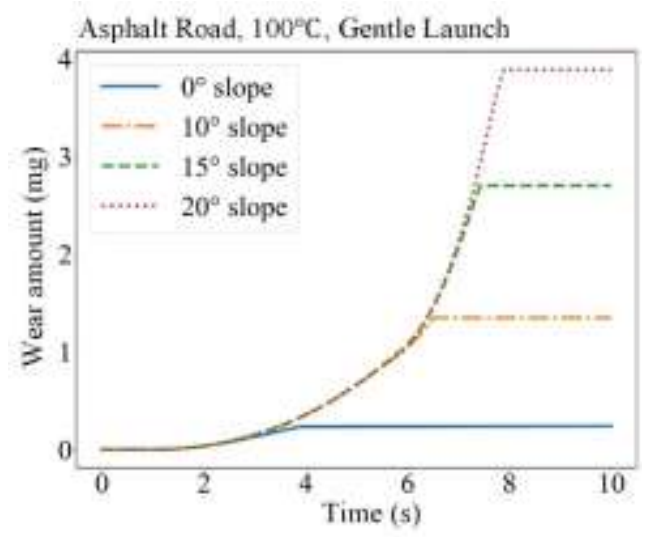

(a) Road slope

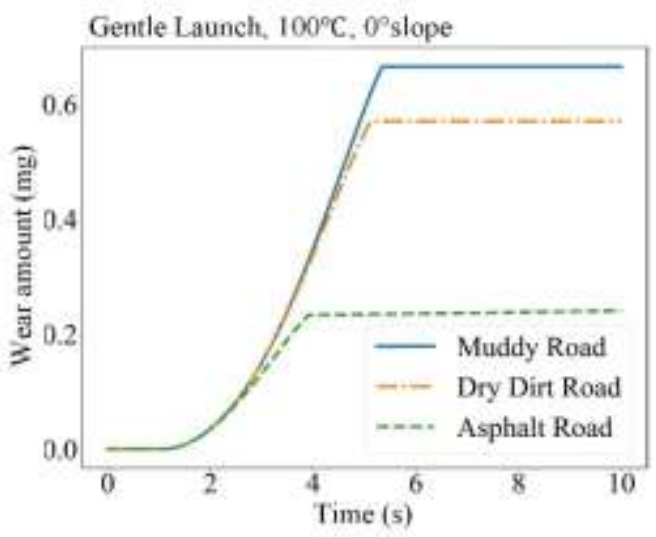

(b) Road type 


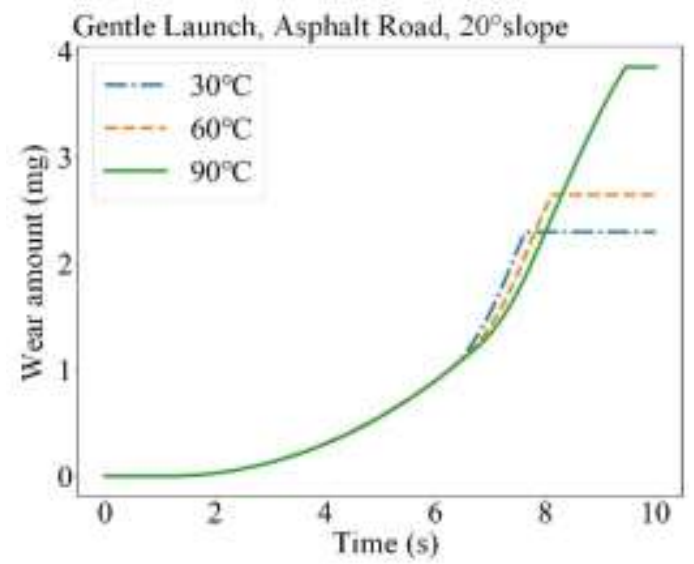

(c) Temperature

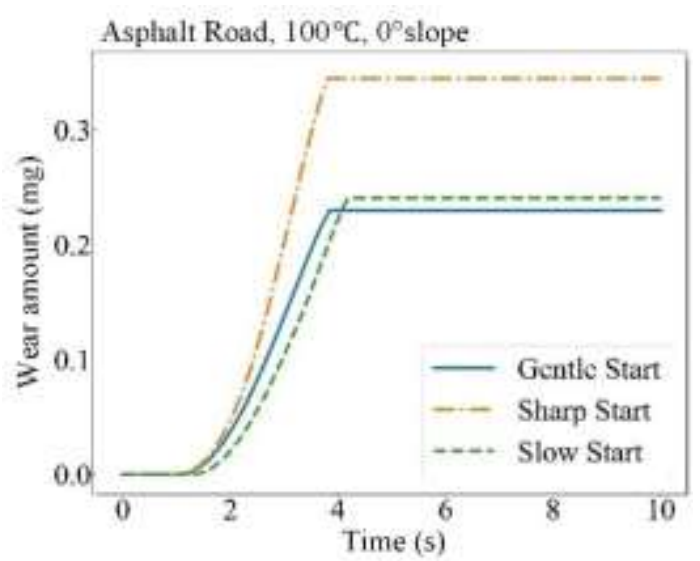

(d) Driver's intention

Fig. 11: Effect of different factors on wear amount.

It can be seen from Fig.11 (a), with the increase of road slope from 0 to 20 degrees, both the sliding time and the wear amount increase significantly. And the wear amount increases from about $0.24 \mathrm{mg}$ to $2.69 \mathrm{mg}$, which increased nearly ten times. This phenomenon is caused by the substantial increase of the vehicle load. As for the Fig. 11(b), it shows the influence of the road types and demonstrates that the road with low road resistance coefficient is effective to reduce the wear amount of the clutch. When it comes to Fig.11 (c), with the increase of the temperature, the wear amount of the clutch rises up from about $1.7 \mathrm{mg}$ to $3.8 \mathrm{mg}$ directly.

Fig. 11(d) indicates the influence of the driver's intention. It can be seen that when starting slowly, the wear amount of the clutch is about $0.24 \mathrm{mg}$, which is between the gentle start (about $0.22 \mathrm{mg}$ ) and the sharp start (about $0.34 \mathrm{mg}$ ). The reason for this phenomenon is that, under the slow start condition, although the grown rate of the wear amount is slow, the gross wear amount accumulates and becomes larger due to the long sliding time.

Based on the above analysis, it can be concluded that the light vehicle load, low environmental temperature and appropriate starting speed will be beneficial to reduce the wear amount and prolong the service life of the clutch.

\section{Conclusions}

(1) A wet pin-on-disc experiment is designed to investigate the wear condition on the contact surface of clutch friction pairs. After the slipping experiments, the wear amount of the friction pair is analysed by the oil analysis spectrometer.

(2) With the increase of the slipping speed, the contact pressure and the temperature, the wear amount shows a growing trend; however, the slipping speed has little influence on the wear coefficient and only the latter two factors are taken into consideration to describe the variation of the wear coefficient.

(3) The dynamic model of the DCT vehicle is established and the wear amount of the clutch is calculated during the launching process under varies conditions. The driver's gentle operation, under light vehicle load and low temperature, will definitely reduce the wear amount of the clutch.

\section{Appendix}

Table 2: Main parameters for simulation.

\begin{tabular}{|c|c|c|c|c|c|}
\hline Symbol & Quantity & Value & Symbol & Quantity & Value \\
\hline$\varphi_{\text {test }}$ & the wear amount of the friction disc & $/$ & $\beta(\mathrm{rad})$ & road grade angle & 0.174 \\
\hline$\delta$ & increasing coefficient of mass & 1.0554 & $\mu$ & friction coefficient & $/$ \\
\hline$A\left(\mathrm{~m}^{2}\right)$ & front area of vehicle & 3.6 & $A_{f}\left(\mathrm{~m}^{2}\right)$ & surface area of the piston & 0.047 \\
\hline$A_{t e s t}$ & the nominal contact area & $/$ & $C_{a 2}$ & damping coefficient of shaft II & 0.5 \\
\hline
\end{tabular}




\begin{tabular}{|c|c|c|c|c|c|}
\hline$C_{a 1}$ & damping coefficient of shaft I & 2 & $C_{i n}$ & damping coefficient of input shaft & 0.5 \\
\hline$C_{a 3}$ & damping coefficient of shaft III & 0.5 & $I_{1}$ & moment of inertia of the shaft I & 0.2102 \\
\hline$C_{D}$ & drag coefficient & 0.62 & $I_{3}$ & moment of inertia of shaft CM & 0.0024 \\
\hline$I_{2}$ & moment of inertia of shaft CL & 0.0024 & $I_{5}$ & moment of inertia of the shaft III & 0.2523 \\
\hline$I_{40}$ & $\begin{array}{c}\text { moment of inertia of the gear on } \\
\text { shaft I }\end{array}$ & 0.0193 & $I_{50}$ & $\begin{array}{c}\text { moment of inertia of the gear on } \\
\text { shaft III }\end{array}$ & 0.0015 \\
\hline$I_{4}$ & moment of inertia of shaft II & 0.2034 & $I_{e}$ & moment of inertia of the engine & 3.65 \\
\hline$I_{i n}$ & moment of inertia of the input shaft & 0.0154 & $I_{R}$ & moment of inertia of vehicle body & 18.902 \\
\hline$I_{\text {in1 }}$ & moment of inertia of engine output & 0.0164 & $K_{a 2}$ & stiffness coefficient of the shaft II & 110088 \\
\hline$K_{a 1}$ & stiffness coefficient of the shaft I & 89389 & $K_{i n}$ & stiffness coefficient of input shaft & 283429 \\
\hline$K_{a 3}$ & stiffness coefficient of the shaft III & 65114 & $N$ & the number of friction pairs & 4 \\
\hline$P_{C}$ & interface contact pressure & $/$ & $R_{i}$ & inside radius of friction disc & 0.086 \\
\hline$R_{o}$ & outside radius of friction disc & 0.125 & $S$ & the relative sliding distance & $/$ \\
\hline$f$ & friction coefficient of road & 0.123 & $i_{1}$ & gear ration(front drive) & 5.3585 \\
\hline$i_{2}$ & gear ration(clutch CM $)$ & 0.92 & $i_{3}$ & gear ration(clutch CL ) & 1.59 \\
\hline$i_{4}$ & gear ration(shaft III) & 0.925 & $i_{5}$ & gear ration(final drive) & 3.818 \\
\hline$m_{(\mathrm{kg})}$ & vehicle weight & 7840 & $I_{W}$ & radius of wheel & 0.1935 \\
\hline
\end{tabular}

\section{References}

[1] P. Walker, B. Zhu, and N. Zhang, "Powertrain dynamics and control of a two speed dual clutch transmission for electric vehicles," Mechanical Systems and Signal Processing, vol. 85, pp. 1-15, 2017.

[2] J. Oh, S. B. Choi and J. Kim, "Driveline modeling and estimation of individual clutch torque during gear shifts for dual clutch transmission," Mechatronics, vol. 24, no. 5, pp. 449-463, 2014.

[3] Y. Yuan, J. Yi, X. Geng, T. Fan and C. Gu, "Research on simulating and modelling dynamics of double clutch transmission (DCT)," The 2nd International Conference on Information Science and Engineering, Hangzhou, 2010, pp. 5344-5348.

[4] X. Cheng and F. Wei, "Starting control of wet double clutch transmission," Journal of Jiangsu University, vol. 26, no. 5, pp. 132-136, 2010.

[5] Z. Zhao, X. Li, L. He, C. Wu and J. K. Hedrick, "Estimation of torques transmitted by twin-clutch of dry dual-clutch transmission during vehicle's launching process," in IEEE Transactions on Vehicular Technology, vol. 66, no. 6, pp. 4727-4741, 2017.

[6] Q. Gu and X. Cheng, "Study on double-clutch transmission gear shift control based on optimal control theory," 2011 IEEE 18th International Conference on Industrial Engineering and Engineering Management, Changchun, 2011, pp. 629-634.

[7] J. Zhang, Y. Yang and G. Jing, "Study on Fuzzy Control of Launch of Dual Clutch Transmission for Heavy Vehicle," Vehicle and Power Technology, 2013.

[8] B. Depraetere, G. Pinte and W.Symens, "A two-level Iterative Learning Control scheme for the engagement of wet clutches," Mechatronics, vol. 21, no. 3, pp. 501-508, 2011.

[9] J. F. Archard, "Contact and rubbing of flat surfaces," Journal of applied physics, vol. 24, no. 8, pp. 981-988, 1953.

[10] G. Fleischer, "Energetische methode der bestimmung des verschleibes," Schmierungstechnik, vol. 4, no. 9, pp. 269-274, 1973.

[11] Q. Ding. "The advance in researches of friction dynamics in mechanics system," Advances in Mechanics, vol. 43, no. 1 , pp. 112-131, 2013.

[12] B. Ma and J. Liu, "Creeping control strategy for direct shift gearbox based on the investigation of temperature variation of the wet clutch," The 20th International Conference on Aerospace, Mechanical, Automotive and Materials Engineering, Paris, 2018, vol. 12, no. 8. 